\title{
The linear life-course imperative
}

One of the more prevalent clichés in Israeli culture is the consolation, "By your wedding day you will feel better." This sentiment is often directed towards small children and is intended to be both comforting and hopeful at the same time. The sentiment not only assures children that with time they'll feel better; it also constantly reminds them of their prospects for the future. In fact, it leaves no room for doubt regarding the heteronormative life-course trajectory, one that leads-eventually, but inevitably-to marriage and children.

Given that marriage is an important milestone, a turning point in one's life course, it is no surprise that similar versions of the same consolation can be found in German, Russian, Spanish, and Portuguese cultures, for example. Indeed, many young girls dress up during Halloween and Purim (a Jewish religious holiday) as brides; the popularity of the "dress up as a bride" game endures. In a similar vein, small girls around the world play with Barbie bridal outfits, and many of the toys marketed at girls, including domestic appliances and little baby strollers, predict a heteronormative, reproductive future. In romantic comedies and television commercials, one often finds sequences where single women reflect on how as young girls, they had already planned their perfect wedding.

Reflecting further upon the consolation: beyond the belief that time heals everything, the wedding is positioned as an indisputable milestone, a life goal, an important transition point in one's life course. Additionally, popular clichés like these guide the child's future life trajectory by emphasizing a linear, heteronormative progression, along which the ultimate destination is visible, clear, and certain. This conceptual temporal frame guides the upset child towards an imagined and desirable future. A prominent cultural channeling process is revealed here, one which predetermines the child's future performance and reflects a collective life scheme. The reassuring and comforting promise predicts an identifiable heteronormative future, one embedded in a set of dominant expectations regarding the valuable and desirable in one's future life course.

In this chapter, I pay close attention to the ways in which this linear telos constitutes some of the major discursive frameworks of the single woman's life trajectory. 
Life-course research has developed extensively since the late 1960s, most notably in the fields of developmental psychology, but also in contemporary anthropological, sociological, and gerontological studies. The resultant abundance of scholarly literature offers a wide variety of conceptual models that simultaneously reflect and produce some of our most pervasive cultural understandings.

My approach to the study of the life course in this chapter integrates a discursive and social constructionist lens, whilst also paying attention to recent theoretical developments in queer time studies. Consequently I view the essentialist and naturalized life-course paradigm as a particularly powerful cultural template. More specifically, my line of research draws upon scholarship which views the notion of the life course as a potent, socially constructed metaphor (Becker 1994; Holstein and Gubrium 2000). James Holstein and Jaber Gubrium, in Constructing the Life Course, point out that the life course is a representational tool, crafted and used in the process of interpreting personal experiences through time (Holstein and Gubrium 2000, x).

This line of analysis attempts to view the life-course construct as an interactional accomplishment; a social form according to which individuals make sense of their everyday lives. This perspective is also reflected in Martin Kohli and John Meyer's (1986) work, which views the life course as a persuasive cultural institution and as an age-graded structure producing time-ordered opportunities and constraints. My analysis views and joins this literature which examines the life course as an ideological-and therefore, fabricated-discourse of existence, including the developmental sequences which are commonly treated as objective and natural features of life.

Such considerations also highlight the manner in which the discursive formation of the life course is standardized and made uniform by what Kohli has described as a life-course regime (Kohli 2007). This regime defines the life course as comprised of rigidly defined sequential developmental stages with administrative rulings (ibid.). According to this perspective, conventional life-course patterns are in-and-ofthemselves social constructs, the consequence of a dominant discursive practice that functions as a core regulator of formal and informal social laws. Life-course models, as Gay Becker notably explains in her study on disrupted lives, serve as the basis for the development of cultural models of how life itself is conceptualized (Becker 1994, 386).

One's life course is often conceptualized in terms of a turning wheel, a flowing river, a life journey, or a life span (Holstein and Gubrium 2000, xi). ${ }^{1}$ We know about the life course from both formal and informal representations, including religious sermons, medical texts, diaries, government documents, and works of art (Shweder 1998, xii). The life course is also seen as a social institution (Kohli 2007), and acts as an integrating force between individuals and their societies. As a key temporal institution, it produces different measures from which one can evaluate one's progression and productivity. From all the above, it can be deduced that the dominant life-course imagery serves as a significant temporal referential frame, through which temporal discontinuities, interruptions, and disruptions are determined.

What is particularly relevant to our analysis here is that the conventional life-course model embodies and defines many social truths concerning individual self-fulfillment, social belonging, and individual movements, predicting in view of these its expected 
progress and decay. Accordingly, it implies fixed temporal categories and expectations. Consider, for example, this passage written by Esti Avisror, an Israeli single woman, in which she reflects on how as a little girl she used to daydream about her future as a married woman and mother:

When I was a child, I would flick through the calendar ... draw flowers and make calculations. I used to think that by the year 2000 - which then seemed so far, and was marked in small numbers-I would be 23 and married, perhaps with a child. I remember, I would close my eyes and wish that I was already there. I believed that this would be the most fulfilling thing that would ever happen to me: I would be a mother. (Avisror 2011)

The above account serves as an example of how the regulatory fantasy of the couple mother-child dyad operates in a context in which the developmental trajectory is fixed and determined. As with many young girls, the writer depicts here how she dreamt of marriage and children, linking these fantasies to ultimate forms of self-fulfillment.

Such examples certify a deterministic life plan with a developmental, linear trajectory, one in which finding a husband and having children are seen as obligatory milestones. According to this view, marriage and parenthood are integral to the life-course progression, and are expected to occur in fixed age cohorts. The concept of life course implies well-recognized categories in the lives of women, and dictates the boundaries of normalcy and sociality. These boundaries are embedded in societal timetables, creating idealized versions of the life course (Roth 1963) and accordingly establish shared expectations and normative judgments. This standpoint emerges from the accounts of many single women. Yael9, a columnist and a single woman, illustrates the interactional dynamic that occurs during family dinners:

All throughout Passover dinner they were silent ... My uncles really held their breath, they were on their best behavior. They were funny; they ate and bragged. Each aunt has a new grandson, each uncle has a secondhand jeep. It was a routine family dinner with many cousins ... I was quite surprised, I could not figure out how they were yet to say anything [about my single status] ... Have I really managed to train them so well? But then my aunt Esther couldn't hold herself anymore and asked the question that we had been waiting for patiently: Well, you have made a career, seen the world but how about bringing a doctor to the family? (Yael9 2006)

The linear progression, from the family one is born into, to the family one establishes oneself, is perceived as an inevitable future trajectory. Yael9 is expected to follow a heteronormative life narrative, consisting of a required transition from adolescence to adulthood, as well as the obligation to continue the family lineage. Elsewhere in the column, she notes that her career and traveling experiences are now perceived as impediments to the desired procreative life course. This is reminiscent of Diane Negra's observation that "women are depicted as particularly beset by temporal problems that may frequently be resolved through minimization of their ambition and reversion to a more essential femininity" (Negra 2009, 48).

These experiences can be appreciated or tolerated up to a certain point, and only as long as they occur at the right time. Single women above a certain age are a threat to the agreed-upon familial and reproductive life narrative. At this temporal juncture, 
their presence as unmarried singles sitting at family dinner tables marks a temporal irregularity (Zerubavel 1981), disrupting the expected temporal generational patterns. Pertinent to this discussion is Judith Halberstam's (2005) criticism of what she views as the middle-class logic of reproductive temporality. Halberstam points out that:

In Western cultures, we chart the emergence of the adult from the dangerous and unruly period of adolescence as a desired process of maturation; and we create longevity as the most desirable future, applaud the pursuit of long life (under any circumstances), and pathologize modes of living that show little or no concern for longevity. Within the life cycle of the Western human subject, long periods of stability are considered to be desirable, and people who live in rapid bursts (drug addicts, for example) are characterized as immature and even dangerous. (Halberstam 2005, 4-5)

Viewed through this perspective, familial life fulfills the pursuit of maturity, continuity, and stability. Complementing Halberstam's analysis, I consider single women to be representatives of a mode of life which defies this customary temporal map, and thus cannot be included with the normative definitions of maturity and civil respectability. The accounts discussed above also reflect the growing temporal awareness of single women. Located in what is grasped as a disruptive temporal stage, their presence draws at this point in time, increasing scrutiny and visibility. The question "When will she marry?" is presented with a sense of urgency, one which expects her to resign to the expected heteronormative timeline.

\section{When will you settle down?}

Daniel Levinson's influential model of the life course (Levinson 1978, 57), outlined in The Seasons of a Man's Life, is an especially fitting starting point for this analysis. Although it was published at the end of the 1970s, it bears much relevance to current imageries of the life course in Israeli and many other societies. Levinson's theory separates adult development into distinctive and sequential stages, including pre-adulthood, early adulthood, middle adulthood, and late adulthood. In this context, I pay particular attention to what Levinson refers to as the early adulthood stage (ages seventeen to forty-five). For Levinson, entrance into the adulthood stage is accompanied by a series of age-related expectations. As such, the thirty-year-old's transition is configured as the period in which one is expected to "settle down," to leave home and to start one's own family.

Indeed, many conventional life-course templates construe this milestone as a critical turning point. In this "settling down" phase, one is expected to "find one's place" and "purpose"; it is a time for realizing one's dreams and potential, a time when crucial choices - namely occupational and marital ones — ought to be made (Levinson 1978). It is pertinent to note here that in recent years, there have been some attempts by psychologically oriented life-course researchers to observe the life trajectories of single women from alternative perspectives. One example can be seen in the work of therapists Natalie Schwartzberg, Kathy Berliner, and Demaris Jacob (1995), who instead of focusing on marriage and childrearing, offer to measure one's life course using 
benchmarks like work, health, and peer networks. Nonetheless, Reynolds rightly criticizes these models as highly prescriptive, and which consequently do not allow women to define their statuses on their own or to maintain a range of different possible options (Reynolds 2008, 29).

Recent studies of singlehood (for example, Byrne 2003; Moore and Radtke 2015; Reynolds 2008; Taylor 2012; Trimberger 2005) also reveal similar alternative paths available to midlife single women. In some of these studies, being single is framed as an asset; accordingly, women describe their solo life course in terms of individuality and of self-actualization. For many single women (mostly those who belong to the middle- and upper-class strata), singlehood has enabled them to pursue satisfying and successful careers. According to Reynolds (2008), this is a different repertoire within which self-actualization and achievement also gain force, in contrast with marriage. "Financial independence is a goal as well as other more diffuse aims of self-fulfillment, all of which may have been hard won. The notion is that there is so much more to life than getting married or looking after other people, and that without these distractions there is more opportunity to achieve desired goals" (ibid., 60).

Despite the existence of such alternatives, more conservative and developmental life-course models undoubtedly continue to prevail in everyday discourses. Everpresent questions continue to confirm a linear and developmental trajectory: So: "When will you get married?" "Don't you think it's time to be more serious?" "What are your future (marriage) plans?” In Hebrew slang, there is an interesting version of the first question here: Matai titmasedi? This can be more or less understood as asking, "When will you settle down?" (i.e. as a legitimate social actor, by participating in the institution of marriage).

The expectation — to be considered as mesuderet (settled) — can be found in a letter from a single woman to her mother. The former apologizes, as she knows how much her mother wants to see her mesuderet (Bat Chen 2009). The etymological root of this Hebrew word-based on the verb lehistader — to become settled or organized-relates to the notion of order, and reflects the importance of creating a stable life structure. In Hebrew slang, it is associated with someone who is well-off or has "made it." Thus, the contemporary slang usage of the word generally denotes economic and personal success; in the context of marriage and family life it refers analogously to someone who is married with children. Indeed, in everyday talk in Israel, one can hear parents discussing whether or not their children are mesudarim or histadru (the present continuous and past tense of the verb lehistader). By the same token, single women often hear the phrase "When will you settle down and bring me kzat nachat [some joy]?"

These everyday expressions correspond with prevailing interpretations of what are perceived to be universal life-course models. Social pressures reflect and dictate a structured life course, prescribed in terms of socially defined and carefully timed transitions. Indeed, the settling-down phase itself is not only a period during which one displays one's own potential, but also a period during which the single person is subjected to immense external pressures and societal requirements "to establish oneself," "settle down," and-as in the Israeli slang-lehistader. In this sense, "becoming established" signifies not just success and happiness, but also the reaching of a watershed in 
time and space. The unjustified delays or non-entrance, by the writers above, into early adulthood is in many respects preventing them and their families from joining the desired and orderly life-course trajectory and expected family cycles.

As Halberstam notes (2005), the marking of time according to dictates of marriage and reproduction are connoted to other temporal schemes of investment, insurance, and capital accumulation. Heteronormative common sense, she stresses elsewhere, leads to:

The equation of success with advancement, capital accumulation, family, ethical conduct, [and] hope. Other subordinate, queer, or counter-hegemonic modes of common sense lead to the association of failure with nonconformity, anti-capitalist practices, nonreproductive life styles, negativity, and critique. (Halberstam 2011, 89)

The Israeli perception of Lehisteder reflects Halberstam's observations, illuminating the close links between orderly life-course narratives and normative familial and conjugal discourses. These temporal schemes, as Halberstam notes, are strongly connected. The re-conceptualization of the life course as a cultural and social institution directs our attention to the significant, mostly taken-for-granted normative framework within which perceptions of late singlehood are constituted and maintained. Most of the texts analyzed for this research echo these rigid normative templates constantly, negotiating with the image of life course and its age-related transitioning. In pursuit of this, I turn now to one of the significant factors influencing the socially and historically situated construction of the single life course: postponement of the age of marriage. This analysis does not attempt to align itself with the demographic scholarship often so preoccupied with the delay of the age of marriage, but will rather shed light on the kind of effect it has on the current temporal production of singlehood.

\section{Taking one's time}

One of the most significant changes in recent demographic and social trends with regard to intimate relations and family schemas is the delay of the age of marriage. In fact, in many societies the postponement of marriage is often encouraged and is associated with demonstrating choice, individuality, and self-fulfillment. From this perspective, marriage is regarded as a mutual choice and as a contractual agreement between two individuals entering a relationship (Giddens 1992; Swidler 2003); the underlying assumption is that they do so only when they are prepared, at the moment that their relationship has reached the "right stage." These understandings are expressed, for example, in the following excerpt from a Ynet column. In the column, the two authors - a psychologist and a family lawyer-outline what they perceive as the three basic requirements for a successful marriage:

- Choose the right person for you.

- Construct the basis of a good and healthy relationship before you decide to get married.

- Nurture the relationship during your time together. (Inhorn and Zimmerman 2007) 
These recommendations reflect some widely shared understandings of the "right recipe" for a good and lasting marriage. The second condition- "Construct the basis of a good and healthy relationship"-epitomizes the changing governing norms concerning when and how to prepare for marriage. From this perspective, marriage requires time and preparation. Thus, the delay of marriage is perceived as appropriate; so much so that marrying too young may now be understood as a hasty and less mature mode of behavior.

Early marriage in contemporary secular Israeli society may trigger responses like: "What's the rush?," "You still have plenty of time," or "You still have the rest of your life ahead of you." The two relationship advisors quoted above express their concerns regarding the manner in which many couples shorten or skip over the "necessary" process of building a good relationship. Some of these couples, they explain, decide to get married before they know one another "well enough."

Choice, preparation, nurturing, readiness, and hard work are some of the prevailing buzzwords in the discourse of intimate relations today (Giddens 1992; Illouz 1997; Swidler 2003). The notion of choice is now endowed with more meaning, as it is based on experimentation, maturity, and-most importantly-preparedness. Accordingly, rushing imprudently into matrimony, it appears, is an act that demonstrates a failure to understand and realize what marriage "really entails." It is sometimes even perceived as the explanatory factor in a break up: "They shouldn't have rushed into marriage so fast." At certain phases in one's life, it is of course preferable to wait, to experiment, and to discover oneself. According to this line of logic, achieving economic independence and accumulating life experience is also highly recommended: finishing college; establishing a career; "taking advantage" of what life on one's own can offer. Being on one's own, living alone, experimenting with different relationships, and not committing too early are just some of the recurring cultural recommendations emerging from these beliefs. "Taking one's time" is a required and a respected cultural injunction.

The next extract demonstrates the writer's hesitations regarding marrying too early, alongside her awareness of the social criticism she might encounter.

I still have time, I know it. I don't want it to happen today. I have no doubt that the age of twenty-one and-a-half is not an ideal age to get married, or to have children. Nonetheless, I already know I want to be there, at the age of twenty-six (after receiving a degree in Communications and being on the verge of a promising career). I want my thentwenty-nine-year-old boyfriend to kneel down and propose. [In my vision], I will agree and will be extremely moved, as I understand that this is not another fantasy wedding plan for the far-off future but a substantial promise for a wedding in the next two months ... Many laugh at me when I relay this vision to them. They think I indulge in childish fantasies ... but I think it's not childishness or immature, but a biological clock that has started ticking earlier than expected ... It seems that we will have to wait patiently for another five years. (Chen 2007)

According to Moran Chen - the writer of this column-her biological clock began to tick earlier than expected. Her wish to get married early is perceived as a childish fantasy. It is interesting to note that when single women delay marriage for too 
long - as will be discussed later in this chapter, they are also accused of being childish and immature. In another Ynet column, a seventeen-year-old single woman who writes to relationship advisers Yael Doron and Gili Bar expresses her hesitation about marrying too young and ending up "like her mother and grandmother, who married their first or second boyfriends and have not experienced anything." On the other hand, she feels that she has found her soul mate, with whom she wants to spend the rest of her life. In response to her question, the two experts explain:

It is reasonable to give yourself some time. In the meantime, you should live in the moment, as is suitable for your age ... And if indeed you continue to feel good with one another as time passes, you could plan the rest of your life together. But in the meantime, give yourselves-both of you-some time. (Doron and Bar 2008)

At this temporal stage of her life, she and her partner are advised to "give themselves time." As they are still considered young, time is still in their possession. The complexity of the demographic and social transitions leading to these social dilemmas is also illustrated in another one of Yael and Gili's advice columns, which depicts this changing social reality:

Many singles are still not coupled for many different reasons. There are those whose order of priorities have led them first to study, to create a secure economic basis, to be independent; and only now are they ready for coupledom. Others had to sort things out for themselves before they were able to turn to committing to long-term relationships, whether it was due to their family of origin, their childhood, or other "baggage" they carried with them. The rest are ... late bloomers; at the age of thirty-three "they've woken up" and have now reached the stage at which their cohorts long ago found coupledom and settled down. (Doron and Bar 2009)

After purportedly illustrating the diversity and complexity of the reasons behind the varied entry points into marriage, the advice column ends, nonetheless, wishing for its readers in bold letters: "May the next date be your first and last!" (ibid.).

Hence, according to Yael and Gili, the rise of single households is a result of a variety of factors. As always, the reasons for singlehood must be deciphered and explained. Yael and Gili rationalize what is considered to be a social aberrance. They point out that some single persons have had to take care of their professional careers and economic independence first, while others were not ready emotionally, or are late bloomers. In other words, late singlehood always has a reason which has to deciphered and accounted for. Nonetheless, the overarching refrain remains: "May the next date be your first and last!"

\section{Speeding up}

You tell yourself that it's ok, you feel wonderful, and you are not pressured yet, but deep inside you know that each man that passes by causes you to consider the possibility of coupledom with him ... meanwhile the clock is ticking. They say that above the age of thirty, girls become hysterical from the pressure to get married. (Or-Li 2008) 
Tamar Or-Li, the single Israeli woman quoted here, describes how her temporal awareness changes, and refers to the well-known metaphor of the biological clock. At this point in her life, she begins to sense that her time is running out. The social message is clear-cut: one should quickly hop on the next train and join the ride before moving from the category of a "late bloomer" to that of the "old maid." As such, I propose that the postponement of marriage is still very much limited by conventional sociotemporal regulations. While getting married at seventeen-or twenty-one for that matter - to a first or second boyfriend has come to signify a premature social move (at this age, one has all the time in the world, and living in a meantime or liminal mode is encouraged), a few years later single women must bear the social responsibility for ignoring their ticking biological clocks.

Consider, for example, the stereotype of the choosy or selective single woman (Lahad, 2013). While in the earlier stages of singlehood her self-determination can be admired and praised, upon reaching what society considers to be a suitable marriageable age - and particularly after passing this - the choosy single woman is perceived as trapped within her own self-regulation. She is the sole saboteur of her future happiness and well-being. At this point in time, her selectiveness marks an overstepping of socio-temporal boundaries, and a disruption of the expected and socially mandated life schedules. ${ }^{3}$

The transition is vivid. Time should be accounted for, should be managed carefully; when a woman is at the prime age for marriage, she should hurry up. At this time, single women are warned again and again that they have no time, or that they are running out of time. At this life stage, time is a sacred and limited resource and accordingly they no longer have the luxury of occupying the "meantime" position and delaying marriage. It turns out that the newly articulated required delay becomes, in a few short years, socially intolerable and unjustifiable.

Merav Resnik, a columnist writing on Ynet explains:

If we don't play the game of life, the game will continue without us. And then one day we will decide to get up from the bench, look around, and wonder how the hell we got here. Sometimes we decide to get up one second before the game is over so that perhaps something could be salvaged from this mess. Sometimes we wake up too late, which brings us to the platform of missed trains ... "Too little, too late" is the slogan of this platform. Those on the platform are standing, waiting, fearful, expecting the train that was here and is now gone ... We [single women] are left on the platform alone. The one who was supposed to hop on with us has boarded the train by himself or perhaps has found someone else to go with. (Resnik 2007a)

Delaying marriage for too long cannot be justified, because at some point one simply "misses the train" for good. As I noted in the Introduction, the train metaphor is abundant in discussions of singlehood. In these accounts the train represents an agreed-upon collective orderly movement, one which reiterates the heteronormative temporal trajectory. One can make it just in time, get on at the right station, join the train, and move ahead with the others, miss the train or take the wrong one. As their singlehood proceeds, the chances of hopping on the right train become minimized. As 
Merav observes cynically, there is a special platform for older single women: "the platform of missed trains." These shared cultural assumptions highlight how time and the socially constructed notions of the life-course are standardized. The hegemonic paradigm of the life course, epitomized in this case by the train, is a reference point against which rigid standards are set. Drawing on the train metaphor highlights the way single women position themselves in relation to dominant life-course models and their dictated rhythms.

The encouraged delay is now re-conceptualized, and regards the "aging single woman" as facing the imminent danger of being left alone on the now deserted platform. Her time slot is squeezed, and it may be deduced that the delay which allowed more time, now poses the risk of leaving no time left at all. Actually, the cultural legitimacy granted to the postponement of marriage substantially shortens the amount of time single women have to find an "eligible partner." Thus, the newfound legitimacy granted to postponing marriage does not, by any means, indicate that single women's time slot is an unlimited one. The years during which they are still "eligible" and "tradable" are just as restricted, yet in a slightly different temporal frame.

What was perhaps viewed as readiness, maturity, and experience at the age of twenty-six, for example, has been drained of its prior meanings and is now considered as an obstacle, indicative of developmental incompetence. For example, the cultural injunction to experience being on one's own, to experience independence, is now replaced by the warning that one will "end up dying alone." As noted above, after a certain period of time, single women can be considered as too independent, too selective, or too lazy (Lahad 2013). In that respect, they are at risk of losing time, therein losing their agency. At this stage, they can no longer take their time. Their age and single status becomes their master status (Becker 2008), and in this respect their deviance from societal timetables could be labelled as "pariah femininities" (Schippers 2007). The refusal to abide by these temporal schemas could potentially contaminate gender relations between men and women. As Schipper explains, a woman exhibiting defiance, physical violence, or authority in a patriarchy can potentially destabilize male dominance, unless the exhibit can be stigmatized and feminized.

This shift in interpretation demonstrates the extent to which personal qualities and behavior are evaluated within these age-based parameters. This now highly condensed timeframe often results in growing pressures, and leads to time panic ambiance. Stanford Lyman and Marvin Scott have defined this type of panic as:

Produced when an individual or a group senses it is coming to an end of a track without having completed the activities or having gained the benefits associated with it or when a routinized spatio-temporal activity set is abruptly brought to imminent closure before it is normally scheduled to end. (Lyman and Scott 1989, 46)

Or, as Negra poignantly claims, one of the characteristics of postfeminist culture "is its ability to define various female life stages within the parameters of 'time panic" " (Negra 2009). In the case of "late singlehood," the routinized temporal patterns addressed here produce and enforce an unequivocal social message: single women 
above a certain age are entering what Reynolds (2008) has termed as the twilight zone. While scanning some of the columns from Ynet discussed earlier, I came across a very telling JDate ${ }^{4}$ advertisement announcing: "Only When You Are Ready: JDate." This message corresponds with the life-course developmental models, and can be grasped as the settling down stage. The advertisement invites the male surfer to find single women between the ages of twenty-five and thirty-four: this temporal framing sheds light on the age-graded system through which singlehood is socially interpreted. This line of analysis will be explored in detail in Chapter 4.

The rapid and confusing social changes of recent decades are reflected in this dialectic. On one hand, viewing singlehood from the socially constructed life-course perspective reflects the dynamic nature of age-related assumptions. On the other hand, embracing a nuanced look at singlehood also reveals that our perceptions of the life course are still very much stage-ordered, implying temporal regular patterns even as they introduce ever changing age-stratification norms.

So far, this chapter has covered some of the striking aspects of the normative life-course model. I now turn to discuss what I view as another significant parameter within the traditional life-course models, the belief in developmental and linear progression.

\section{The linear trajectory}

The centrality of the linear logic is demonstrated by the conventional thinking about "late singlehood." Single women are constantly asked, explicitly and implicitly: "What's going on?" "What's new?" "Any news?" An abundance of visual images depict single women as waiting for a telephone call, for a sign, or for "Mr. Right." Warnings, such as "In the end you will die alone," and blessings and consolations like "By your wedding day you will feel better," suppose a continuous and coherent linear life trajectory. I argue that the comforting tone adopted in a phrase addressed to an upset childlike is embedded into a heteronormative destiny, one which determines a linear path that will certainly lead one to one's wedding day. Getting married captures the promise and the pervasive expectation that at a certain point everything will "work out," and that the temporary disrupted order will accordingly rearrange itself.

Moreover, these blessings signal crucial signposts which structure and bestow meaning upon the measurements and movements of time. From this standpoint, when one wishes a single woman: "Bekarov ezlech!" (Soon at yours [wedding]!), this expectancy forms part of a normative injunction emphasizing a linear developmental order. In Chapter 7, I analyze in greater detail the ways in which this blessing marks a climb up a linear temporal ladder, wherein single women can join the social order once they are married. My contention is that, according to this logic, the single woman is located in a symbolic heteronormative queue, within which all she can hope for is to move forward and shorten her wait to the minimum. Here, I wish to stress that this blessing reflects the manner in which our social life is constantly organized and regulated by temporal linear indicators, as well as by the ways in which participation in this pathway is highly encouraged. 
In Julius Roth's study of the temporal experiences of patients in hospital, Roth was particularly interested in how the structure of time imposes certainty and predictability upon the trajectories of hospitalized patients:

One way to structure uncertainty is to structure the time period through which uncertain events occur. Such a structure must usually be developed from information gathered from the experience of others who have gone or are going through the same series of events. As a result of comparisons, norms develop for the entire group about when certain events may be expected to occur. When many people go through the same series of events we speak of this as a career, and of the sequence and timing of events as a career timetable. (Roth 1963, 136)

Roth's evaluation can be applied to the Bekarov ezlech blessing or to reoccurring statements like "By your wedding day you will feel better." The social knowledge expressed here takes the form of collective benchmarks and sign posts. In this way, information is gathered from the experience of others, constant comparison seeming to hold the entire group together. In a similar vein, the career timetable of the Israeli single woman is prescribed in advance, and social injunctions therefore spur her to move forward in a pre-defined and recognized linear trajectory. The linear trajectory of a woman's life course is utterly predictable.

Linear time's most powerful claim, observes Carol Greenhouse (1996), lies in its own redemptive power in relation to individual life. This hope and belief is expressed, for instance, in the well-worn cliché, "Don't worry, eventually you will find true love." Not only does it presuppose a long linear journey, but it also offers individual redemption and salvation. Queries, such as "What are you waiting for? "What's new?" are set within this linear logic. Heteronormative and patriarchal assumptions structure time, and in this sense imply that all that the single woman can hope for is to "move forward in life" and find the right guy to marry.

The linear homogenous time also assumes a linear causality model providing one with a utopian telos. In contrast, this mode of explanation- "In the end you will die alone"-echoes the reasoning of a linear trajectory, one which makes an indisputable connection between the present and the future. For an unmarried woman, her future holds nothing but misery and loneliness. Thus this statement can be interpreted as the single woman's diminishing agentic ability to determine her future. As a consequence, these dreary forecasts acquire deterministic-linear and even fatalistic undertones. Long-term singlehood represents a non-progressive, non-developmental linear path. The image of the train is especially relevant here. It accentuates not only the importance of being on time, but also the sequential linear track composed of a chronology of life stations determined by basis of age.

This formulation also fits well with what Anthony Giddens (1990, 1991) views as modernity's obsession with the colonization of the future. Embracing such an approach entails the promise of attaining greater mastery of one's life trajectory and bestowing one with certainty and predictability. Within this dominant framework, heteronormative expectations constitute singlehood as "being on the way": the journey might take some time, yet the desired destination is certain. In a similar fashion, singlehood also 
feeds into what Zygmunt Bauman (1996) has termed a modern individualistic pilgrimage. Bauman writes that unlike the pilgrimages of pre-modern times, the pilgrimage of modern individuals is accomplished without them actually leaving the home. In modern society, this journey is not a choice but a mode of life. Hence, the world of the pilgrim is orderly, predictable, assured, and progressive:

\begin{abstract}
For pilgrims through time, the truth is elsewhere; the true place is always some distance, some time away. Wherever the pilgrim may be now, it is not where he ought to be, and not where he dreams of being. The distance between the true world and this world here and now is made of the mismatch between what is to be achieved and what has been. The glory and gravity of the future destination debases the present, plays down its significance and makes light of it. For the pilgrim, what purpose may the city serve? For the pilgrim, only streets make sense, not the houses-houses tempt the tired wanderer to rest and relax, to forget about the destination or to postpone it indefinitely. Even the streets, though, may prove to be obstacles rather than help, traps rather than thoroughfares. They may misguide, divert from the straight path, lead astray. (ibid., 20)
\end{abstract}

Bauman's conceptualization of the spirit of pilgrimage expands our understanding in relation to some of the common representations of the existential experiences single women might expect. The liminal position of singlehood is likewise configured as always being "somewhere else," and the emphasis placed on the future destination reminds us all that the single woman is where she is not supposed to be, both spatially and temporally.

Prevailing images of single women today are still formulated and constituted in much the same way as the modern pilgrim metaphor. The roads to "Mr. Right" are the streets through which the single woman should march. There are no houses in which she can rest and forget about her future destination. From this perspective, Ulrich Beck and Elizabeth Beck-Gernsheim have underscored how the pressures to construct one's life as a biographical project or do-it-yourself biography stress the contemporary injunction for individual life planning (Beck and Beck-Gernsheim 2002, 3). This line of analysis will be developed further in the coming chapters, but for our purposes now it suffices to note the clear connection between individuality and linear time. Individual self-identity, as Ÿian (2004) puts it, is reflected through images of the future self. For Ÿian, the future-oriented mode of constructing identity is performed by universalizing and individualizing aspects of linear time in terms of conceived uniqueness and autonomy:

In general self-identity tends to be mirrored in images of oneself in the future. This is a future that is understood as open space to be realized by individuals. Such a conception of the future is provided by linear time in cognitive and ideological categories where individualism and linear time appear to be two sides of the same coin ... linear time cannot be properly understood unless seen in relation to individualism. Firstly, the individuation of people that historically has taken place through citizenship, wage-work, money and commodities can hardly be seen independently of chronometric instruments of linear time (the clock and the calendar). Secondly, it is by highlighting our wishes and ambitions for the open future that we can escape the constraints of the present on the 
autonomy that is preconditioning the experience of our own individuality as persons. (ibid., 175)

In his work on the temporal experiences of the unemployed, Ÿian contends that the unemployed lack the basic qualifications that would enable them to participate in the collective linear temporal orientation; therein, they experience no sense of certainty or progression from the present to the future. A similar claim could be made in relation to widespread beliefs about "late singlehood." By not joining the collective linear path, single women are commonly perceived as lacking the basic properties which would in turn enable them to join the collective movement forward.

In this context and before concluding, it is important to note that linear visions of the future are interwoven with cyclical ones. Cyclical temporal idioms permeate conceptions of private and personal life. Birth and death, the rise and fall of generations, the transformation from dust back to dust, marriage and parenting, all follow cyclical rhythms (Daly 1996; Greenhouse 1996, 23). From this outlook, the construction of family life exhibits many cyclical qualities. For instance, when one wishes for the single woman to get married soon, linear conceptions are employed to attain familial continuity. Thus, the concurrent search for continuity, repetition, progress, and change in the normative construction of family life is expressed in both linear and cyclical temporal formations. The power of these temporal forms resides in the constant pressure to move forward within the linear trajectory, and to reintegrate into society by following both linear and cyclical rhythms. Lifelong singlehood, then, is configured as an aberration and a distraction from appropriate modes of linear and cyclical temporality. Single women are identified as the living representation of this irregularity: they are perceived as wasting time, putting their lives on hold, or living in empty time. In the next chapter, I will try to further understand the ways in which this disruption is fabricated and enhanced.

\section{Notes}

1 See also Becker (1994).

2 For example in 2007, Israeli TV broadcasted a sitcom called Mesudarim, about four Israeli friends who "made it" by selling their high-tech start-up company and becoming millionaires. The term could also be read in gendered terms. In Israel the term is generally used to refer women who have succeeded in getting married, usually alongside having had their own property and a steady job. From this perspective, single women in Israel cannot fit the mesuderet rubric.

3 See my discussion of single women's selectiveness, Lahad (2013).

4 A popular internet dating site. 